\title{
LA PROMOCIÓN VOCACIONAL Y LA VIDA RELIGIOSA
}

DOI: https://doi.org/10.52039/seminarios.v51i178.687

Autor: Carmen Margarita Fagot, rscj. Ex presidenta de la CLAR (Conferencia latinoamericana de Religiosos.) Provincial en Puerto Rico y Asesora de PJ.

Desearía invitarles a hacer un espacio dentro de nosotros y nosotras mismas para acoger a aquellos jóvenes a quienes conocemos en nuestros países y en nuestros barrios, colegios y universidades, jóvenes que van a la Iglesia y a aquéllos que ya no van y preguntarles: ¿dónde te encuentras generalmente, qué buscas, cómo piensas, qué sientes?

Si hiciéramos lo mismo con nosotros y nosotras mismas y con los sacerdotes, religiosos y religiosas que conocemos y planteáramos las mismas preguntas, ¿estarían nuestras respuestas distantes o cercanas de las respuestas de los jóvenes? Me atrevería a decir que bastante distantes. El día que podamos acercar más estos dos mundos, jóvenes y religiosas y religiosos nos encontraremos buscando juntos caminos de seguimiento de Jesús más acordes con el mundo de hoy desde las vocaciones especificas.
Tras invitarnos a un acercamiento al mundo actual, sus relaciones y mostrarnos que no todos los jóvenes están desorientados, que loshay en búsqueda. Propone como vocación primera la vocación humana y se pregunta si en este momento es adecuado hablar de 'promoción vocacional'.. 
¿Estamos dispuestos a cambiar nuestra mirada sobre la juventud de hoy para buscar junto con ellos caminos de seguimiento de Jesús?

¿Cómo hablar de vida religiosa y de promoción vocacional sin preguntarnos sobre la crisis de la vida religiosa y sobre la crisis de la Iglesia hoy? Quizás haya que empezar cuestionando el término promoción vocacional o levantando preguntas sobre la crisis de la vida religiosa hoy como institución o colocar en relieve la crisis de todas las religiones institucionalizadas, y la de nuestra Iglesia Católica entre éstas, antes de hablar de promoción vocacional. Creo que tenemos ante nosotros y nosotras un gran desafío. ¿Será válida la promoción vocacional, como alternativa de "marketing" de un estilo de vida que como institución está en crisis? ¿A qué estilo de vida queremos invitar a los jóvenes?

Al parecer no hemos entrado en una nueva crisis en la Iglesia sino que la crisis suscitada alrededor del Concilio Vaticano II no ha terminado. Parece haber cobrado más fuerza. Esta crisis no es propiedad de la Iglesia Católica. Los historiadores observan que ya hubo en la historia de la humanidad una crisis de similar envergadura. Hubo un gran cambio cultural alrededor de 500 años antes de Cristo en muchas regiones del mundo ${ }^{1}$. Y no podemos negar que estamos viviendo un cambio de época que es difícil pero a la vez fascinante. Cambio de época influenciado o provocado también por el sistema neoliberal y la globalización.

Aunque vivimos en un mundo en crisis y en algún momento de este encuentro hablaremos de él, deseo más bien invitarles a cambiar la mirada sobre los jóvenes y sobre la vida religiosa. Miren que realizo algo nuevo; ya está brotando, ¿no lo notan? (Is 43,19). Desearía invitarles a mirar y descubrir lo evangélicamente contestatario desde lo pequeño; acercarnos a la religiosidad del joven y su encuentro con Dios como desafío; a abrirnos a las nuevas generaciones que afrontan y reelaboran la crisis por la que pasa la sociedad y a preguntarnos cómo su manera de hacerlo cuestiona la vida religiosa tal como es vivida hoy.

Reflexionaremos también sobre la vocación humana, el seguimiento de Jesús y la vida religiosa en un mundo en crisis y en búsqueda. Aunque hay un tesoro en la vida religiosa nos plantearemos ¿para qué vida reli-

${ }^{1}$ Comblin, José. Los interrogantes de la vida religiosa en el Siglo XXI. Traducido por Paulo Sartor SJ para la Revista Diafonía No.112, diciembre 2004, pp. 5-6, de la Revista Convergencia, Brasil, 370 (Marzo 2004), pp. 76-95. 
giosa y para qué misión llamar, convocar? Y por último nos preguntaremos si el término "promoción vocacional" es el más adecuado para dar a conocer una manera específica de seguir a Jesucristo.

Miren que realizo algo nuevo; ya está brotando, ¿no lo notan? (Is 43,19)

No sé si influenciados por una sociedad que mide por grandes números nos hemos acostumbrado a ver la vida desde las "mayorías" o desde las grandes cantidades y hemos ido perdiendo de vista que lo de Dios, lo nuevo, se manifiesta a través de pequeños brotes. En lo pequeño se muestra lo de Dios nos dice el profeta Isaías. Como dice el Evangelio: encontrarán a un niño pequeño recién nacido, envuelto en pañales, y acostado en una pesebrera le dijo el ángel a los pastores (Lc 2,12). ¿Quiénes son y donde están los jóvenes que quieren seguir a Jesús y cuyas nuevas expresiones, simbologías y búsquedas cuestionan profundamente los modelos de vida religiosa actuales? ¿Qué experiencias hay de un nuevo estilo de seguimiento de Jesús afín con la tradición de la "sequela Christi"llamada vida religiosa? Y si no las hay, ¿por qué?

Es cierto que los jóvenes no existen aislados de la sociedad en que vivimos y en ésta se van dando cambios que son decisivos en el conjunto de transformaciones por las que estamos pasando. Las nuevas formas de producción de bienes de consumo y de servicios se abren a una especie de conquista del macrocosmos y del propio ser humano. Estas formas desvían la atención sobre la verdadera Vocación del ser humano. El saber tecnológico se torna en una forma privilegiada de poder económico y político. Está en manos de unos pocos que tienen acceso a este conocimiento, esto crea mayor exclusión. La mayoría de los jóvenes latinoamericanos y caribeños están entre los excluidos. ¿Qué posibilidades de seguimiento de Jesús existe en personas sin conciencia de su vocación humana?

En un mundo donde la técnica influye en las relaciones entre los seres humanos con su medio ambiente, grupos, clases, sociedades e individuos las expresiones de globalidad y la dinámica de globalización son parte de esto. Sin embargo en medio de la homogeneización de la cultura y la fragmentación de las personas hay jóvenes que buscan su integración personal, valoran lo intercultural y aprecian las diferencias entre los seres humanos. La concentración de poder lleva a experimentar profundas desigualdades pero frente a esto algunos tienen una fuerte sensibilidad soli- 
daria. Se promueven las relaciones esporádicas y sin embargo hay jóvenes que buscan ir más allá de éstas y crean lazos de amistad y ayuda mutua.

Los jóvenes están inmersos en un mundo donde la producción de sentido y de significado con que vemos las cosas, las personas, y a nosotros mismos controla al ser humano. Esto es los medios de comunicación y las grandes instituciones intentan colocar el sentido de la vida en el consumo y en la producción de "commodities" (lo que nos hace sentir bien), en la relativización de valores etc. Existe una estrecha relación que entrelaza las formas de producir y consumir los bienes con el horizonte de significados que alimentan la vida. El consumo afecta no sólo el juego económico sino nuestro propio modo de ser. Se habla de una crisis de sentido donde hay un acento en la individualidad, la autonomía de los sujetos, en las exigencias de la subjetividad que parecen relativizarlo todo. Otros están completamente excluidos de ese mundo que parece dar sentido pero a la vez son víctimas de la propaganda que les hacer desear aquello que el neoliberalismo ofrece como sentido de la vida. Este proceso lleva a confundir lo que es la vocación del ser humano: ser persona capaz de decidir su propia vida, ser sujeto de su propia historia, ser sujeto junto con otros y otras que también son sujetos. Sin embargo, en medio de esto, encontramos jóvenes que ayudan a otros a encontrar el sentido de sus vidas y luchan por encontrar el sentido de las suyas y ser sujetos de su propia historia.

La relativización de sistemas, de significados elaborados colectivamente y trasmitidos en los procesos de socialización implica la crisis generalizada de las instituciones que han sostenido durante décadas la socialización de los individuos. Es cierto que los jóvenes en sintonía con la cultura postmoderna privilegian al individuo y parecen estar más volcados a los valores e intereses individuales que a la transformación de la sociedad. Es cierto que muchos sienten una gran inseguridad personal que carga con una autoestima precaria que parece reclamar un nido afectivo. Pero también es cierto que hay jóvenes dispuestos a trabajar en equipo junto con otros en la búsqueda de alternativas más humanas y más ecológicas para construir un mundo más habitable. Algunos jóvenes cuestionan las instituciones porque no son éticas o porque anteponen las estructuras de poder ante el valor del individuo. 
Religiosidad y encuentro con Dios como desafio

La tendencia al sincretismo religioso en los jóvenes hoy y su relación con Dios se limita muchas veces a la esfera de lo privado, pero también hay que tener en cuenta las nuevas formas de religiosidad. Es importante la acogida de las distintas expresiones de religiosidad. La nueva religiosidad acentúa la libertad en la búsqueda de lo divino, cada uno es agente vital, no receptor pasivo de una doctrina. Procura un camino propio en la experiencia religiosa. Parece haber en ellos un retorno a la religión de la naturaleza y a la comunión con el cosmos. Es cierto que hay una cierta desvalorización de la razón y de la historia como lugar de salvación y es en la comunión con el cosmos y con el Yo donde encuentran lo divino.

El ser humano es considerado como divino. Por un lado Dios es impersonal, para muchos es energía y vibración. Dios y el mundo se confunden, lo que importa es el Todo, la fusión en ese Todo. En la meditación y la interiorización se busca la experiencia de trance y de éxtasis religioso que lleva a la conciencia a colocarse fuera del mundo de lo cotidiano. El cuerpo y la mente unidos llevan a lo esotérico. Algunos rechazan la mediación salvífica de Jesucristo².

Este modo de vivir la religiosidad presenta nuevos desafíos a la experiencia del Dios de Jesús en los jóvenes hoy día. Cómo acompañar a los jóvenes en su búsqueda de Dios, de un Dios personal que tiene que ver con la existencia es nuestro desafío. Un Dios que tiene que ver con mi persona con mi crecimiento personal, con mis heridas y mis capacidades, con mi posibilidad de relacionarme con otros y con el vivir la experiencia de fraternidad en la comunidad cristiana, un Dios que tiene que ver también con mi compromiso histórico. ¿Cómo acompañar a jóvenes que buscan la respuesta al sentido de su existencia fuera de sí manipulados por los seudo-valores del neoliberalismo? ¿Y los jóvenes a quienes el sistema obliga a experimentar sin estar preparados para asumir las consecuencias de sus decisiones, cómo colaborar con ellos para aprender a optar y asumir la vida?

Sin embargo, a pesar de todo esto va emergiendo una espiritualidad que descubre al Dios vivo que habla a través de la Escritura, pero también

\footnotetext{
${ }^{2}$ Cfr. Terrin, A. Natal, Nova era. A religiosidade do postmoderno. São Paulo. Loyola 1996.
} 
a través de todo lo que nos hace trascender. Se abre una dimensión de contemplación de la naturaleza, el amor y el arte.

Hay en los jóvenes un compromiso ecológico en defensa de la tierra. Una espiritualidad que revaloriza a nuestra tierra sacramento de Dios comunión como responsabilidad de todos y todas. Espiritualidad que busca unir el deseo, la experiencia de ser hijos, de ser amigos, de ágape.

Surge una espiritualidad penetrada de la experiencia de la belleza, experimentando a Dios en la danza, la poesía, los colores, las formas de las esculturas. Un Dios experimentado también sensiblemente. Experiencia que une lo ético, lo estético y lo religioso. Comienza a experimentarse una espiritualidad que supera el individualismo con un fuerte sentido de comunidad abierta ${ }^{3}$. Me parece que esto confronta algunos de nuestros modos de vivir la vida religiosa.

Las nuevas generaciones afrontan y reelaboran la crisis por la cual pasa la sociedad

Por lo tanto el reto está más bien en llegar a entender cómo las nuevas generaciones afrontan y reelaboran la crisis por la cual pasa la sociedad. Encontramos jóvenes que quieren ser sujetos y compañeros en la construcción de la vida y sus significados. Estos desean entrar en diálogo con nosotros y nosotras y en ese diálogo encontrar juntos lo que es ser persona hoy, y cuál es nuestra vocación humana. Anhelan encontrar a Dios en sus vidas y vivir desde la experiencia de Dios que van descubriendo en sus vidas.

La juventud tiene su manera de afrontar la crisis del mundo actual. Hay jóvenes a quienes llamo "sobrevivientes saludables" de la sociedad actual porque su modo de ser no se ha dejado absorber por los antivalores mencionados en este escrito. Siento que algunos rasgos comunes de las subcultura juveniles saben a libertad. Una libertad diferente a lo que nosotros consideramos libertad. Un rasgo podría ser la relativización de los valores tradicionales, puesto que se prefiere la vida sin criterios absolutos, se valora más lo flexible que lo estable y definitivo. Las instituciones las valoran en cuanto sirven para mejorar la calidad del encuentro entre personas.

${ }^{3}$ García Rubio, Alfonso. Elementos de antropología teológica. pp. 138 -141). 
Hay una actitud tolerante y pluralista ante la diversidad. Se da un alto valor a la amistad. Los jóvenes tienen mucho sentido lúdico y festivo. Hay una disposición a la solidaridad, pero sin empeño en obligaciones permanentes. Aunque hay cierta renuncia a transformar al mundo creo es más bien una búsqueda de un reformismo sensato y concreto, quizás más realista que la de nuestra generación, en el cual muchos se implican.

Percibo que hay en las subculturas juveniles unas fortalezas que son las que cuestionan y que están impregnadas de huellas del Reino. Hay en ellos/as una gran capacidad de gozar, de disfrutar la vida presente y de llenar de sentido cada tramo de la existencia, bajo el signo de la gratuidad y de la alegría. En ellos hay una búsqueda de autenticidad y mayor libertad para cuestionar y ahondar en la fidelidad a sí mismos. Para ellos/as la centralidad de la persona les lleva a rechazar toda forma de ideologización que sacrifique a la persona en función de las ideas. Se les descubre un sentido de los propios límites que les ayuda a reconocer lo que deben recibir del otro.

Hay en ellos/as capacidad de rebeldía contra aquello que no sea realmente digno del ser humano, aunque haya sido recibido por tradición. El pragmatismo lleva a muchos/as a poner más el amor en las obras que en las palabras. La búsqueda de sentido, de identidad, de pertenencia les hace poner un acento fuertemente existencial en sus motivaciones. Su manera de relacionarse entre hombres y mujeres es de mayor igualdad. ¿No son estas expresiones de cómo vivir el amor de unos con otros con naturalidad, libertad y sencillez?

Las nuevas expresiones, simbología y búsquedas de la juventud hoy cuestionan profundamente los modelos de vida religiosa actuales. (Ver Anexo 1: Las nuevas generaciones....).

La vocación humana, el seguimiento de Jesús, y la vida religiosa en un mundo en crisis y en búsqueda

El año pasado caminaba por unos campos de trigo al sur de Chile y me preguntaba ¿de dónde le viene la fuerza al trigo que parece tan frágil ante el daño que hace la cizaña? La fuerza de la vida es mayor que la de la muerte. Así me parece está sucediendo en nuestra tierra latinoamericana y caribeña si logramos mirarla con los ojos de la fe. El Dios de la Vida tiene que ver con nuestra existencia, Si pudiéramos descubrirlo así nues- 
tro continente sería diferente y nosotros y nosotras seríamos diferentes, aunque no podamos negar la crisis de la sociedad en que vivimos.

Si entendemos que cada ser humano está llamado a escoger y desarrollar la riqueza constitutiva de ser persona y asumir lo que significa ser persona podríamos decir que es ésta la primera y fundamental vocación de cada ser humano ${ }^{4}$. Sin embargo el neoliberalismo, reforzado por el patriarcalismo en las instituciones parece estar convirtiéndonos en hombres y mujeres sin vocación. ¿Qué es ser persona en una sociedad donde ésta no cuenta, si no es para consumir bienes, productos, naturaleza, o donde la persona no tiene la posibilidad de participar de aquellos bienes y servicios que ayudan a vivir una vida humana digna? Eres persona en cuanto tienes, sabes, produces, dominas, gozas de comodidades... parece estar diciéndonos la sociedad que se nos quiere imponer como modelo de felicidad y sentido como seres humanos. Hoy nosotros vemos a las personas fragmentadas, desintegradas, sin sentido de la vida, individualistas, quizás sin capacidad de vivir en diálogo con otros y otras. Vivir en comunidad es algo que parecía hasta inherente en el ser humano. Las instituciones han ido secando también la vocación humana, puesto que las personas que están llamadas a escoger y desarrollar la riqueza constitutiva de ser persona y asumir lo que significa ser persona, muchas veces son absorbidas por las leyes y estructuras de las instituciones, dejando poco espacio o ninguno para que la persona pueda desarrollar la riqueza constitutiva de lo que son.

Si la primera vocación del ser humano es vivir como persona "A imagen y semejanza de Dios nos creó. Hombre y mujer nos creó" (Gn 2, ...). ¿Por qué se nos está haciendo casi imposible vivir como tales hoy? ¿Por qué es tan difícil pensar que sí es posible vivir unas relaciones de amor, hermandad, justicia, paz, creatividad, diálogo en medio de la sociedad en que vivimos? El poder vivir de esa manera nos hace semejantes a lo que Dios quiere para sus hijos e hijas. Me pregunto ¿cómo ha de desarrollarse una segunda vocación, la de vivir como seguidores y seguidoras de Jesucristo si no puedo vivir como persona? Como bautizados y bautizadas estamos llamados a vivir el seguimiento de Jesús y que éste sea el centro de nuestras vidas. Esa relación sólo se puede dar cuando nos damos cuenta de que la vida de Cristo tiene que ver con la nuestra. Desde una

${ }^{4}$ Cfr. García Rubio, Alfonso. Unidade en la pluralidade, cap. 7, p. 303-317. 
relación de persona a persona su proyecto se convierte en mi proyecto: el de amar como el Padre ama, el hacer mío su proyecto.

A través de la historia hemos conocido hombres y mujeres que quisieron vivir el seguimiento de Jesús, el de amar de manera radical. Algunos lo han vivido individualmente, otros en pareja y otros y otras sin que fuera su intención contagiaron ese deseo y alrededor de su manera de vivenciar el evangelio se formaron movimientos, institutos a los que se ha llamado vida religiosa. Sabemos que hoy día se está cuestionando esta institucionalización, pues a través de la historia se ha ido sacralizando a las personas que han formado parte de estos grupos. A veces de manera tal que hasta se le llegó a llamar a este estilo de seguir a Jesús estado de perfección o santidad. Separando a estas personas del resto del pueblo de Dios ya fuera por el hábito como signo de consagración o por los privilegios que por pertenecer al instituto se le fueron dando 5 .

Sin embargo El Reino de Dios está en medio de nosotros (Cfr. Mc $1, \ldots)$ en una sociedad que gime con dolores de parto. Nos parece que el gran desafío para los llamados seguidores de Jesús o cristianos sigue vigente: ¿cómo descubrir el Reino, cómo colaborar para que acontezca, cómo hacerlo acto? Tenemos que cuestionar lo que entendemos por ser cristianos y también los paradigmas que sustentan los modelos de vida religiosa. Hemos de atrevernos a crear nuevos paradigmas, y preguntarnos si la vida religiosa tiene aún como institución algo específico que ofrecer a la Iglesia y al mundo de hoy del modo como está viviendo.

\section{"Donde está tu tesoro está tu corazón"}

Me atrevería a decir que el tesoro de la vida religiosa está en la centralidad en Jesucristo, en su seguimiento, en su modo de ser persona que ama y se relaciona al estilo de Jesús . ¿No es esto lo central del cristianismo? Un cristianismo que según Metz, Bloch y Marcusse no es recuerdo sino memoria activa, memoria peligrosa y liberadora de Jesús ${ }^{6}$. Es considerar a Jesús como decisivo, determinante, normativo en todas las relaciones: con Dios, con los demás, con la sociedad, con la naturaleza, con

\footnotetext{
${ }^{5}$ Ibíd. Comblin.

${ }^{6}$ Cfr. Alegre, Xavier. Memoria subversiva y esperanza para los pueblos crucificados. Editorial Trotta. Madrid 2003.
} 
el cosmos. Es poder decir como dice San Pablo "Mi vivir es Cristo". Aunque no somos los religiosos y las religiosas los únicos seguidores de Jesús, esa es nuestra vocación.

¿A qué Jesús queremos seguir? Al Jesús que pone en acto los deseos del Padre allí donde están más claras las contradicciones. Jesús vive unido al Padre, "el Padre y yo somos uno" (Jn 14,11). Llega a conocer los gustos del Padre, su sueño para la humanidad y para la creación. Jesús vivió la decisión del Padre: pone en acto el Reino de Dios. Así lo dice cuando comienza su vida publica "El Reino está en medio de nosotros, cambien de vida y de corazón" (Mc 1,15). Jesús ama a la manera del Padre: da pan a los hambrientos, libera a los cautivos, endereza a los que ya se doblan, da vista a los ciegos, sustenta al huérfano y a la viuda, reconoce la dignidad de los niños, denuncia el trato injusto hacia la mujer, toca al leproso, vive la vida cotidiana como un ser humano que ama la vida y entra en comunión con las personas. Se convierte en el Revelador del Padre. Con su manera de vivir como ser humano viene a subvertir la historia, las relaciones. En el aquí y el ahora7. ¿No será esta la vida y misión del religioso y la religiosa? ¿No será este el nuevo paradigma de la vida religiosa?

Para muchos la vida religiosa es un proyecto de vida que impulsa obras: obras de misericordia, de educación, de salud, de pastoral y que se consagra a Dios por medio de tres votos: castidad, pobreza y obediencia. Pero la vida religiosa no es sólo eso. La vida religiosa se recrea o no tiene lugar en la Iglesia ni en el mundo. Para recuperar su sentido cada religioso y religiosa no tendría que desear seguir a Jesús y poner en acto lo que revela el Padre y a la vez descubrir lo que el Padre revela a sus hijos e hijas y en la creación: el amar en la vida cotidiana. Caminar juntos hombres y mujeres de buena voluntad que buscan la construcción de un nuevo mundo posible como actores sociales. Hace acto el poder vivir ese otro modo de ser humanos, al estilo de Jesús en la vida cotidiana, desde el amor, en el cuidado de la creación, en la búsqueda de la justicia, en la solidaridad con otros y otras que buscan el sentido de sus vidas, en comunión con el cosmos. Vivir sin deshumanizarnos por el activismo, el individualismo, el consumo y la competencia. Resistir en la esperanza de la Vida como resisten nuestros pueblos.

${ }^{7}$ Cfr. Notas Clase Sinópticos. ITIPRI, julio, 2005. 
Seguir a Jesús cuya vida proclama una vida alternativa (diferente) porque recupera el sentido de la existencia como finalidad, que es lo que tiene sentido. Con su modo de vivir recupera una creación negada, recupera el sentido de la vida de un pueblo que no surgió para ser sombra, sino para ser pueblo, un ser humano que no nació para ser manipulado ni utilizado sino para ser persona ${ }^{8}$. Esto quiere decir vivir una vida que supone el escoger y desarrollar la riqueza constitutiva de ser persona y asumir lo que significa ser persona. Estar en continuo crecimiento como sujeto: persona-en comunidad, en nuestra experiencia espiritual y en nuestro compromiso histórico, en la vida cotidiana, junto a la vida cotidiana de nuestros pueblos.

Por eso la vida religiosa se pregunta hoy, ¿cuál es la alternativa humana que nuestra vida proclama, como mujer, como hombre? Si la existencia es finalidad y no el quehacer cómo tendría que ser nuestra existencia? Si dejáramos que Dios desatase en nuestra vida lo que desató en Jesús: el que el Reino aconteciera, ¿cómo sería nuestra vida religiosa si viviéramos de esa decisión? Si no fuera así, nuestra vida de seguimiento perdería sentido. ¿Acaso el reforzar estructuras patriarcales, leyes, liturgias vacías de vida es lo que le da sentido a la vida religiosa?

\section{¿Llamar, convocar para qué vida religiosa y qué misión?}

Para muchos la vida religiosa se ha vaciado de su verdadero contenido, La vida religiosa se ha convertido en una clase privilegiada en la sociedad 9 . ¿Por qué se dice esto?

Somos pueblo de Dios, no somos parte de la Jerarquía de la Institución Eclesial, somos hombres y mujeres bautizados que hicimos una opción de seguimiento de Cristo dentro de una Institución llamada vida religiosa, pero la opción no es por la institución "per se" sino por el seguimiento de Jesucristo. Por lo tanto el cómo lo instituyente se ha ido institucionalizando es siempre cuestionable. ¿No se tratará también de recuperar la dimensión laical de la vida religiosa y ser pueblo entre el pueblo, sin privilegios, sino sencillamente vivir el amor al prójimo, y cuidar de la

\footnotetext{
${ }^{8}$ Cfr. Cabarrús, Carlos R. Bitácora. Cuaderno para acompañar caminantes. Serendipity, Madrid, 2000.

${ }^{9}$ Ibíd. Comblin.
} 
creación? Nos estamos cuestionando el contenido jurídico de los votos, pues muchas veces suena a palabras vacías.

Los jóvenes de hoy cuestionan con sus vidas o permanecen indiferentes a la vida religiosa o la buscan como refugio. Lo cuestionan también los religiosos y religiosas que van perdiendo el sentido de sus vidas, que viven en depresión, sin sentido porque la institución ha apagado algo en sus vidas. Aunque sabemos que son una minoría los escándalos sexuales y de corrupción ética dentro de la Institución Eclesial y religiosa, el que suceda también cuestiona la vida religiosa como institución. ¿Para qué vida religiosa queremos convocar?

Si vemos la historia de la vida religiosa ésta nació desde un deseo, de hombres y mujeres laicos y laicas, de vivir de manera radical el Evangelio. Su vida cuestionó la forma de vivir el Evangelio de la Institución Eclesial misma, sobre todo en el modo de administrar el poder y las riquezas y cuestionó también las estructuras anti-evangélicas del mundo en que surgió. La vida de estos laicos y laicas fue entendida como alternativa evangélica al mundo. ¿No tendría pues la vida religiosa que recuperar su dimensión laical, y caminar con otros bautizados desde lo que ésta va descubriendo como su aporte específico dentro de la vida y misión de la Iglesia? ¿No tendríamos también que cuestionar la deshumanización y el patriarcalismo?

En respuesta a esta situación y al llamado de su Santidad Juan Pablo II de buscar en fidelidad creativa al Espíritu en Vita Consecrata, algunas religiosas y religiosos dentro de sus propias instituciones se están dando a la tarea de búsqueda de alternativas ante la crisis que se vive como vida religiosa. Van encontrando caminos nuevos sencillos de intercongregacionalidad, de unión con laicos y laicas, de mayor cercanía con el pueblo y van experimentando la minoridad, la insignificancia. La unión entre la mística y la profecía (en el sentido de búsqueda del bien común) en la vida cotidiana, podría ser un camino, sin asegurar tampoco que ese es el camino. Los religiosos hermanos van queriendo recuperar su ser laical pues así redescubren su misión en el mundo. Pero no se tienen respuestas contundentes sobre lo que es significativo hoy.

Ya en Europa y en los países del primer mundo se pregunta la vida religiosa: ¿De dónde sacar en esta soledad el pan que necesitan nuestros pueblos? (Mc 8,1-11). En algunos de nuestros países de América Latina y sobre todo del Caribe, podríamos decir que la vida religiosa ya empieza a 
vivir esa inmensa soledad. Su vida como institución empieza a perder significado, aunque hay individuos dentro de las congregaciones cuya vida sigue teniendo mucho significado. ¿Esta soledad que empieza a experimentar la vida religiosa, la vive como gracia o como tentación? La situación eclesial ha cambiado mucho también en los últimos años. La Iglesia y la Jerarquía van perdiendo influencia, su estilo de vida es cuestionado por muchos y otros se muestran indiferentes. Se acabaron los años de gloria. La vida religiosa se debate para encontrar un lugar de significado dentro de la misma iglesia.

La inserción entre los pobres que llegó a cuestionar la vida de muchos ha perdido fuerza. Aunque encontramos muchas religiosas y religiosos en inserción otros nos vamos convirtiendo en un grupo más que participa del temor a los barrios pobres en las grandes urbes, por la violencia que se vive en ellos. Al parecer se ha debilitado la opción por los pobres. Tampoco se fue protagonista de un cambio. Aun así algunos religiosos van descubriendo que aún nos falta aprender de nuestros pueblos, de los empobrecidos, de los indígenas, de los negros que están aún más marginados, de las mujeres, los jóvenes y los niños. Se empeñan en participar junto con ellos de la rutina de la vida cotidiana, aprendiendo de su resistencia ante la dureza de la vida. Religiosos y religiosas descubren que ya no vienen a salvar sino a convivir vivir con el pueblo de Dios su vocación de hacer presente el amor de Dios, y a descubrir y colaborar en el acontecer del Reino. Van tomando conciencia de que no se trata tampoco de ser protagonistas del cambio sino que vivir el evangelio tiene que ver con la existencia misma, con el modo de vivir el amor al estilo de Jesús. Y eso en sí está lleno de sentido.

Cuando vivimos esta soledad que vamos sintiendo como tentación creemos que el irnos aferrando más a las reglas, a las estructuras inflexibles, a las grandes obras, al protagonismo es lo que atraerá a los jóvenes. Se van al interior de nuestros países en busca de vocaciones. $\mathrm{Y}$ a veces, sin darnos cuenta, nuestros conventos se llenan de muchos jóvenes que en su mayoría no son sobrevivientes saludables de esta sociedad, sino que buscan en la Iglesia y en la vida religiosa una vida segura, cómoda y pasiva. Desgraciadamente buscan vivir de y para la religión, vestir el hábito que les puede dar el estatus que añoran. Buscan salir de una realidad con la expectativa de alcanzar otra que le ofrecería aquello que le falta por problemas financieros, dificultades sociales. Imaginariamente la vida reli- 
giosa se le presenta como la puerta de nuevas posibilidades. Para algunos como posibilidad de identificación apaciguando su angustia por falta de referencias. Para otros y otras como promesa de completarse ante imágenes temporarias y fragmentadas como si la institución le fuera a dar en su imaginario lo que le falta ${ }^{10}$.

También se da el caso de aquellos que en la manera estructurada patriarcal de las congregaciones buscan la figura paterna o materna que suple, acoge, apacigua a los afligidos y angustiados. Buscan una imagen masculina de poder, inconscientemente un ethos seguro donde cultiva inconscientemente su dependencia y anulación. O buscan una imagen materna que todo lo suple anulando personas y creando dependencias también. Jóvenes con dificultades afectivas, de relación, de autoestima, de identificación sexual, que buscan resolver sus conflictos en la experiencia religiosa y en el grupo religioso, como lugar puro y angelical, convirtiendo a la comunidad religiosa en refugio de su homosexualidad o lesbianismo o de relaciones agresivas sin control, también están buscando la vida religiosa ${ }^{11}$. ¿Tendríamos que preguntarnos si es este el tipo de jóvenes que son los llamados a la vida religiosa, o no?

¿Para qué tipo de vida religiosa? En una sociedad donde se está dando un cambio cultural donde la mujer está logrando el lugar que le corresponde como persona, a veces las religiosas no tiene la oportunidad de hacerlo. ¿Por qué algunos de nuestros Señores Obispos, y sacerdotes siguen promoviendo este tipo de vida religiosa: sumisa, sin formación humana ni teológica?

Sin embargo, a pesar de la crisis mencionada muchos religiosos y religiosas han comenzado un proceso de refundación de la vida religiosa yendo a las fuentes. Se cuestionan si el estilo de vida religiosa que están viviendo se podría cambiar por un estilo más significativo para el mundo de hoy. Animados por la CLAR buscan cómo vivir hoy una vida mística y profética.

Se dan también hoy otras búsquedas en los caminos de seguimiento de Jesús: grupos ortodoxos, con estructuras y prácticas quasi medievales; comunidades mixtas de sacerdotes, laicos, laicas, solteros y casados, con-

10 Cfr. Castilho, William César. A Formacâo Religiosa en Questaço. Editora Vozes, Petrópolis, 2004. pp. 127-130 (Traducción personal libre).

11 Frei Antonio Moser, citado en p.156, Ibíd. 
sagrados, religiosos y religiosas, grupos radicales en pobreza y compromiso con los excluidos. Todos esfuerzos válidos en cuanto a la búsqueda, más algunos cuestionables en cuanto al fundamentalismo y la estructura patriarcal. Siento que aún tenemos el desafío de examinar algunas de estas formas de vida religiosa. Me parece que todo aquello que no es fiel a la vocación humana, deshumaniza y por lo tanto es cuestionable.

Algunas y algunos religiosos nos estamos preguntando ya, si no es el momento de llamar de otra manera a este modo de seguir a Jesús que tiene que ver con la existencia, ya que la vida misma es misión, seguimiento en el modo de amar como Jesús ama en el evangelio. La existencia misma tiene que ver con el acontecer del Reino y desde la entrega total a Jesús en los pobres y excluidos. ¿No es toda vida religiosa si es cristiana? No se trata de distinguirnos unos de otros sino de vivir el Evangelio y seguir a Jesucristo, cuya memoria viva es peligrosa, porque habla de Reino.

¿Será el término promoción vocacional el adecuado para dar a conocer una manera específica de seguir a Jesucristo?

¿Qué desafíos presenta a la llamada "promoción vocacional" el caminar junto a jóvenes y adultos que quieren otro mundo posible y buscan el seguimiento de Jesús en un proyecto de vida que hoy día está en crisis? ¿Será adecuado el término "promoción vocacional" para describir ese deseo de que los jóvenes y las jóvenes hoy se sientan seducidos por Jesucristo y también quieran seguirle de una manera especifica, en un estilo de vida cuyo centro sea el amor?

La vida religiosa hoy es un estilo de vida en cambio, en proceso de recreación, de refundación desde el carisma de los fundadores y desde nuevos carismas que surgen en la Iglesia teniendo en cuenta la historia de la vida religiosa y su misión dentro de la Iglesia. La vida religiosa se recrea hoy desde procesos de crecimiento de la persona - la comunidad -la espiritualidad- y el compromiso histórico transformador en continua interrelación ya que la vida misma es misión, no una tarea o una obra.

Quizás más que trabajar una promoción vocacional habría que trabajar una pastoral juvenil que ayude a los jóvenes a descubrir su vocación como seres humanos, como sujetos y dentro de esta vocación su llamada desde la fe a seguir a Jesucristo. Un proceso como éste supone acompañar a los jóvenes para que se constituyan en sujetos de sus propias vidas, capaces de discernir el sentido de sus vidas y crear sus propios proyectos de vida. Acompañar procesos donde los jóvenes lleguen a vivir un compromiso que 
brote de la integración personal y que se nutra de la experiencia del Dios de Jesús para buscar y hacer posible el reinado de Dios para la humanidad, un proyecto de justicia de igualdad, de hermandad, de equidad de género, de respeto y defensa de la ecología a través de proyectos y estructuras sociales de acuerdo a su edad. Jóvenes que aprendan a vivir como un ser para los demás afectados por el sufrimiento de las otras personas ${ }^{12}$.

Trabajar una pastoral de encuentro y de armonización. De Encuentro 13 consigo mismos, con los demás, con el Dios de Jesús y con la misión. De Armonización promoviendo procesos hacia la armonía personal, la armonía espiritual y hacia un compromiso histórico armónico. Me parece que tendría que ser una pastoral cuyo énfasis esté en el proceso de humanización. Esto es una pastoral que acompaña procesos de discernimiento personal, desde una relación de persona a persona. Promoviendo procesos de crecimiento de la persona, - de la persona en comunidad - crecimiento en la espiritualidad, esto es la experiencia de fe, de una fe encarnada en la historia personal y en la del pueblo - y crecimiento en el compromiso histórico transformador. No puede haber discernimiento vocacional si no hay sujeto $^{14}$. Tenemos el reto de jóvenes de zonas rurales que entran a una vida religiosa urbana, a una Iglesia urbana con una pastoral muchas veces rural.

Tenemos más interrogantes que respuestas. $\mathrm{Y}$ hay caminantes jóvenes sí, necesitados de hermanos y hermanas que les provean de alguna bitácora que les acompañe en el camino a veces claro y a veces oscuro de búsqueda de nuevos horizontes.

\section{Concluir nunca, continuar sólo con esperanza}

Hoy a los religiosos y religiosas nos toca vivir la vida sin muchas certezas, pero a la vez vivir como quien su existencia ha sido cambiada por el amor. Para muchos de nosotros y nosotras nuestra vida y nuestra búsqueda está llena de sentido y queremos transformarla, aún cuando las vocaciones disminuyen.

12 Cfr. Cabarrús, Carlos R. Cuaderno de Bitácora para acompañar caminantes. Serendipity, Madrid, 2000.

13 Cfr. Proyecto Conéctate, 2001. Provincia Puerto Rico-Haití. Religiosas del Sagrado Corazón de Jesús.

14 Cfr. Cabarrús. Ibíd. 
Si la religiosa y el religioso vive alegre como quien descubre el Reino porque Dios hace nuevas todas las cosas. Si cuida su ser y actúa como quien su vida y su persona es Reino y en ella acontece el Reino porque descubre a Dios en todo y ama al hermano y la hermana como si fueran hermanos propios hasta dar la vida. Si vive en constante proceso de crecimiento como persona, como parte de una comunidad, y nutre su espiritualidad y vive su compromiso histórico transformador en constante interrelación con estos cuatro elementos. Si va descubriendo que no hay espiritualidad sin sujeto, ni compromiso histórico sin comunidad ni espiritualidad; y no hay espiritualidad sin persona ni comunidad, ni sin compromiso histórico, descubrirá que su existencia misma es misión pues el Dios de Jesús tiene que ver con su existencia y la suya con la de Jesús. El marketing no es necesario sino la vida en seguimiento como memoria viva de Jesús. De todas maneras algunos querrán seguir a Jesús, al ver a otros vivir o inventarán nuevos modos. A nosotros y a nosotras, nos tocará acompañarles en su búsqueda.

Hoy solo nos toca cambiar, vivir buscar y acompañar por caminos desconocidos. Mañana el Espíritu suscitará jóvenes que quieran también vivir y buscar y seguir a Jesús. Continuaremos caminado con esperanza, pues, aunque amamos el ser religiosos y religiosas, sabemos que la Institución vida religiosa no es lo esencial sino la vida misma en seguimiento de Jesús de una manera más humana, amando al estilo de Jesús. Así nos lo acaba de decir Dorothy Stang, religiosa de Notre Dame de Namur quien arriesgó su vida y fue asesinada en Anapu, Pará, en Brasil el 12 de febrero 2005 compartiendo la vida con campesinos, caminando con ellos en su lucha por sus derechos, una más como cientos de campesinos e indígenas que reclaman a los fazendeiros un pedazo de tierra para vivir una vida digna. Una entre muchos que también han sido asesinados... Su existencia nos ha hablado sin palabras: la Institución vida religiosa no es lo esencial sino la existencia vivida en amor, en seguimiento como memoria viva y peligrosa de Aquél a quien seguimos. Gracias Dorothy, hermana. 
Anexo 1. Las nuevas generaciones...

Las nuevas generaciones*

Opción por relaciones interpersonales y horizontales: preferencia por las relaciones democráticas, de tolerancia, horizontales y abiertas. Los grupos de amigos son más valorizados que las relaciones de familia

Los jóvenes están inmersos en un mundo donde la producción de sentido y de significado con que vemos las cosas, las personas, y a nosotros mismos controla al ser humano y se confunde lo que es la vocación del ser

Jóvenes dispuestos a trabajar en equipo junto con otros en la búsqueda de alternativas más humanas y más ecológicas. Los jóvenes cuestionan las instituciones porque no son éticas o porque anteponen las estructuras de poder ante el valor del individuo.

¿Cómo acompañar a los jóvenes en su búsqueda de Dios, de un Dios personal que tiene que ver con la existencia?

* Cfr. Castillo Pereira, William Cesar. A formacao religiosa en questao. Editora Vozes Ltda. Petrópolis. 2004.

\section{La Vida Religiosa*}

¿Están las comunidades religiosas preparadas para recibir este tipo de jóvenes?

¿Cómo ayudar a ser personas capaces de decidir su propia vida, ser sujeto de su propia historia, ser sujeto junto con otros y otras que también son sujetos, y no hombres y mujeres dependientes, como algunas estructuras en la VR crean?

¿Están las religiosas y los religiosos en su mayoría dispuestos a trabajar en equipo? ¿Qué lugar tiene lo ecológico en nuestras comunidades?

Las estructuras muchas veces son más valorizadas que las personas. ¿Son todas las comunidades éticas? ¿Qué hacer ante la criticidad de los jóvenes ante la estructura Eclesial? 
Preferencia por el sincretismo religioso y por las formas religiosas ecuménicas

Comienza a surgir una espiritualidad que supera el individualismo con un fuerte sentido de comunidad abierta.

Encontramos jóvenes que quieren ser sujetos y compañeros en la construcción de la vida y sus significados. Estos desean entrar en diálogo con nosotros y en ese diálogo jóvenes que van a aceptar todo. encontrar juntos lo que es

Ser persona hoy, desean encontrar a Dios en sus vidas y desean vivir desde la experiencia de Dios que van descubriendo en sus vidas.

Relativización de los valores y de las tradiciones: escoger experiencias sin criterios absolutos. Se valoriza más lo flexible y momentáneo, se desea gozar el momento presente.

Desinterés por la macro política y las grandes estructuras, mayor inclinación por las pequeñas transformaciones que por las grandes obras y revoluciones

¿Cómo entra en un compromiso definitivo, en una vida estructurada y que valoriza mucho las tradiciones y que muchas veces les quita libertad?

¿La formación en qué dirección va? Muchos son continuadores de las grandes obras de la congregación. $\mathrm{O}$ conviven con los religiosos y
¿Cómo encajan en las comunidades nuevas expresiones religiosas?

Muchas congregaciones no están preparadas para este tipo de jóvenes, en una estructura patriarcal. A veces se acepta en el grupo aquellos religiosas que fueron gestores del cambio en los 70'. 
Tendencia al hedonismo y con una vulnerabilidad psicológica: dificultad en la reelaboración de momentos de frustración, tiempos de espera, de Necesidad de ayuda psicológica. angustia opción preferencial por el ¿Lo hacen las congregaciones? placer, el entretenimiento el consumo inmediato.

No tiene una forma única y establecida de vivir, sino una múltiple visión Choque con lo establecido, choque de la vida, la muerte, Dios, las insti- entre generaciones. tuciones lo establecido. 